уДК 616-036.22

DOI 10.17816/pmi35542-50

РЕЗУЛЬТАТЫ ИЗУЧЕНИЯ ДЕЗИНФЕКТАНТОУСТОЙЧИВОСТИ БАКТЕРИЙ, ВЫДЕЛЕННЫХ ОТ ПАЦИЕНТОВ, В МИКРОБИОЛОГИЧЕСКОМ ОБЕСПЕЧЕНИИ ЭПИДЕМИОЛОГИЧЕСКОГО НАДЗОРА ЗА ИНФЕКЦИЯМИ, СВЯЗАННЫМИ С ОКАЗАНИЕМ МЕДИЦИНСКОЙ ПОМОЩИ В МНОГОПРОФИЛЬНОЙ МЕДИЦИНСКОЙ ОРГАНИЗАЦИИ

Д.Д. Нестерова ${ }^{1,2}$, А.Н. Нешатаев ${ }^{1}$, Н.В. Лукъяненко ${ }^{1 *}$, А.А. Петрова ${ }^{2}$, В.В. Прокопьев ${ }^{1}$, Т.С. Сергеев ${ }^{1}$

${ }^{1}$ Алтайский государственный медицинский университет, г. Барнаул, ${ }^{2}$ Краевая клиническая больнища, г. Барнаул, Россия

\title{
RESULTS OF STUDYING DISINFECTANT-RESISTANCE OF BACTERIA, EXCRETED FROM PATIENTS IN MICROBIOLOGICAL PROVISION OF EPIDEMIOLOGICAL SURVEILLANCE OF HCAI AT MULTITYPE MEDICAL INSTITUTION
}

\author{
D.D Nesterova ${ }^{1,2}$, A.N. Neshataev ${ }^{1}$, N.V. Lukyanenko ${ }^{1 *}, A . A$. Petrova $^{2}$, \\ V.V. Prokopyev ${ }^{I}$, T.S. Sergeev ${ }^{I}$ \\ ${ }^{1}$ Altai State Medical University, Barnaul, \\ ${ }^{2}$ Regional Clinical Hospital, Barnaul, Russian Federation
}

\begin{abstract}
Цель. Совершенствование микробиологического мониторинга дезинфектантоустойчивости микроорганизмов, выделенных из клинического материала, в эпидемиологическом надзоре за инфекциями, связанными с оказанием медицинской помощи.

Материалы и методы. За период 2012-2016 гг. в ходе мониторинга устойчивости было проведено 3320 исследований клинического материала. Количество исследованных микроорганизмов - 1557. Выделено 337 штаммов дезинфектантоустойчивых микроорганизмов. Исследования микроорганизмов из клинического материала на устойчивость проведены к 48 дезинфицирующим средствам 15 групп с различными действующими веществами.
\end{abstract}

( С Нестерова Д.Д., Нешатаев А.Н., Лукьяненко Н.В., Петрова А.А., Прокопьев В.В., Сергеев Т.С., 2018 тел. +7 (3852) 566924

e-mail: natvalluk@mail.ru

[Нестерова Д.Д. - аспирант кафедры эпидемиологии, микробиологии и вирусологии; Нешатаев А.Н. аспирант кафедры эпидемиологии, микробиологии и вирусологии; Лукьяненко Н.В. ("контактное лицо) - доктор медицинских наук, профессор кафедры эпидемиологии, микробиологии и вирусологии; Петрова А.А. заведующий эпидемиологическим отделом; Прокопьев В.В. - кандидат биологических наук, доцент кафедры эпидемиологии, микробиологии и вирусологии; Сергеев Т.С. - ординатор кафедры эпидемиологии, микробиологии и вирусологии]. 
Результаты. В ходе исследования установлено, что микробиологический мониторинг, ориентированный на непрерывное слежение за циркуляцией микроорганизмов среди пациентов, позволил увеличить количество исследований в 2016 г. в 2,6 раза, сократить общее количество дезинфектантоустойчивой флоры в 2016 г. на 62 \%. Наибольший удельный вес выделенных культур был в отделениях хирургического профиля - 48,8 \%, в отделениях реанимационного профиля - 30 \%, терапевтического - 21,2 \%. Клинический материал, из которого получены положительные результаты, определялся промывными водами (от 43,5 \% в отделении хирургического профиля до 74,8 \% в терапевтических), кровью на стерильность (от 2,7 \% в терапевтических до 31,4 \% в реанимационных отделениях). Микрофлора, выделенная из клинического материала, представлена преимущественно P. Aeruginosa - 24,0 \%, Kl. pneumoniae - 30,0 \%, E. coli - от 12,9 до 22,1 \%, St. aureus - от 3,0 до 7,6 \%. Проведенные исследования дезинфектантоустойчивости к 48 наименованием 15 групп химических соединений свидетельствуют о нарастании резистентности к четвертичным аммониевым соединениям (ЧАС), в том числе ЧАС + амины - 24,7 \%, ЧАС + альдегидсодержащие - 6,8 \%, хлорсодержащие - 21,9 \%. Наиболее высокая резистентность к используемым дезинфектантам зафиксирована у Acinetobacter spp., Kl. Pneumoniae, P. Aeruginosa, E. coli.

Выводы. Разработанный алгоритм микробиологического исследования позволил на основе программного обеспечения создать базы данных, вести направленный мониторинг эпидемиологически значимых микроорганизмов, обеспечить корректировку выбора дезинфицирующих средств, тактики дезинфекции.

Ключевые слова. Микробиологический мониторинг, бактериологические исследования, этиологическая расшифровка, микробный пейзаж, клинический материал.

Aim. To improve microbiological monitoring of disinfectant-resistance of microorganisms, excreted from clinical material in epidemiological surveillance of HCAI.

Materials and methods. Over the period from 2012 to 2016, while conducting resistance monitoring, 3320 investigations of clinical material were performed. The number of studied microorganisms was 1557. The number of excreted disinfectant-resistant microorganism strains was 337. The studies of microorganisms from clinical material for resistance were realized to 48 disinfectants of 15 groups with different reactants.

Results. During the present study it was established that microbiological monitoring, oriented for continuous monitoring of microorganisms circulation will permit to increase the number of studies in 2016 by 2.6 times, to reduce the total number of disinfectant-resistant flora in 2016 by $62 \%$. The greatest weight of excreted cultures was in the units of surgical profile $-48.8 \%$, resuscitation profile $-30 \%$, therapeutic one $-21.2 \%$. Clinical material, from which positive results were obtained, was determined by scourage (from $43.5 \%$ in the surgical unit to $74.8 \%$ in therapeutic), blood sterility (from $2.7 \%$ in therapeutic units to $31.4 \%$ in resuscitation units). Microflora, excreted from clinical material is presented predominantly by $P$. aeruginosa - $24.0 \%$, Kl. pneumoniae - $30.0 \%$, E. coli - from 12.9 to $22.1 \%$, St. aureus - from 3.0 to $7.6 \%$. The studies regarding disinfectant-resistance to 48 items from 15 groups of chemical compounds are the evidence of growing resistance to QAC, including QAC + amines $24.7 \%$, QAC + aldehyde-containing - $6.8 \%$, chlorine-containing - $21.9 \%$. The highest resistance to disinfectants used was in Acinetobacter spp., Kl. pneumoniae, P. aeruginosa, E. coli.

Conclusions. The developed algorithm of microbiological study, based on software, permitted to form the database, to monitor epidemiologically significant microorganisms and correct choice of disinfectants and disinfection tactics.

Key words. Microbiological monitoring, bacteriological studies, etiological decoding, microflora, clinical material.

\section{ВВЕДЕНИЕ}

В крупной многопрофильной медицинской организации больничная среда представляет собой сложную динамическую искусственную экологическую систему, оказывающую влияние на заболеваемость инфекциями, связанными с оказанием медицинской помощи
(ИСМП) [6-8]. Для объективной оценки состояния госпитальной экосистемы проводится микробиологический мониторинг. При современном развитии медицинских технологий он приобретает все болышее значение [6, 8, 9]. На организменном уровне он используется для этиологической расшифровки ИСМП, оценки антибиотико- и фагорезистентности, 
дезинфектантоустойчивости, принятия управленческих решений по лечению и антибиотикопрофилактике $[1,5,7,9]$.

На популяционном уровне применяется специалистами для прогнозирования эпидемиологической ситуации, лабораторного обеспечения эпидемиологической диагностики, оценки частоты колонизации пациентов. Важным в этой области является изучение свойств циркулирующих в больничной среде микроорганизмов (степень вирулентности, антибиотикорезистентности, устойчивость к дезинфицирующим средствам) и определение штаммов, получивших приоритетное распространение $[2,4,5]$. Все эти аспекты необходимы для прогнозирования эпидемической ситуации по ИСМП и определения госпитальных штаммов микроорганизмов на учрежденческом уровне [2, 4].

Микробиологический мониторинг дезинфектантоустойчивости микроорганизмов, выделенных из клинического материала, позволяет обеспечить наблюдение за микрофлорой, привносимой в стационар, и ее распространением по отделениям, выявить связь с медицинскими манипуляциями, их инвазивностью и агрессивностью [2, 4]. Он обеспечивает возможность контроля за формированием госпитальной флоры. Сочетание мониторинга клинического материала и внешней среды обеспечивает эффективную систему надзора и определяет комплекс профилактических и противоэпидемических мероприятий $[2,4]$.

Основные проблемы микробиологического мониторинга ИСМП связаны с недостаточным внедрением современных микробиологических методов исследования в рутинную практику лабораторий медицинских учреждений, ограниченными возможностями внутривидового типирования штаммов микроорга- низмов, включая генотипирование на региональном уровне [2, 6, 7]. Проблемой является отставание технической, кадровой обеспеченности лабораторий, осуществляющих микробиологическую диагностику гнойносентических инфекций (ГСИ) $[1,2]$.

Исходя из изложенного мониторинг дезинфектантоустойчивости микроорганизмов, выделенных из клинического материала в медицинской организации, с полным изучением и сопоставлением их биологических свойств, нацеленный на своевременное выявление внутрибольничных штаммов, является весьма актуальным для профилактики ИСМП.

Цель исследования - совершенствование микробиологического мониторинга дезинфектантоустойчивости микроорганизмов, выделенных из клинического материала, в эпидемиологическом надзоре за ИСМП.

Задачи:

1. Предложить алгоритм мониторинга дезинфектантоустойчивости микроорганизмов, выделенных из клинического материала, в эпидемиологическом надзоре за ИСМП в многопрофильной медицинской организации.

2. Оценить уровни контаминации клинического материала пациентов в отделениях хирургического, реанимационного и терапевтического профилей в многопрофильной медицинской организации.

3. Оценить видовой состав микроорганизмов из клинического материала в отделениях различного профиля в многопрофильной медицинской организации.

4. Определить устойчивость к дезинфицирующим средствам микроорганизмов от пациентов в отделениях различного профиля в многопрофильной медицинской организации. 


\section{МАТЕРИАЛЫ И МЕТОДЫ ИССЛЕДОВАНИЯ}

Материалами исследования послужили данные официальной статистической отчетности, информационные, аналитические материалы, учетно-отчетная документация, а также результаты лабораторных микробиологических исследований, проведенных в 2012-2016 гг. в КГБУЗ «Краевая клиническая больница».

В работе использованы МУ 4.2.2942-11 «Методы санитарно-бактериологических исследований объектов окружающей среды, воздуха и контроля стерильности в лечебных организациях»; МУ № 287-113 по дезинфекции, предстерилизационной очистке и стерилизации изделий медицинского назначения от 1998 г.

При определении чувствительности/устойчивости к дезинфицирующим средствам руководствовались методическими рекомендациями «Способ определения чувствительности микроорганизмов к дезинфицирующим средствам», разработанными ГОУ ВПО «Нижегородская государственная медицинская академия Федерального агентства по здравоохранению и социальному развитию», Министерством здравоохранения Нижегородской области, Управлением Роспотребнадзора по Нижегородской области.

Выращивание бактерий и их подготовка к определению чувствительности/устойчивости к дезинфекционным средством проводились на средах и при условиях, оптимальных для культивирования каждого вида (рода), группы. Выбор тест-объектов, методика исследования и интерпретация результатов - согласно методическим рекомендациям «Способ определения чувствительности микроорганизмов к дезинфицирующим средствам». Оценка степени чувствительности: полная при отсутствии роста; неполная при наличии роста (суббактериальное действие - 100-299 КОЕ/мл, неполное бактерицидное действие - от 1 до $99 \mathrm{KOE} / \mathrm{мл);} \mathrm{ус-}$ тойчивость при росте 300 КОЕ/мл и более).

За период 2012-2016 гг. в ходе мониторинга устойчивости было проведено 3320 исследований клинического материала. Количество исследованных микроорганизмов составило 1557. Выделено 337 штаммов дезинфектантоустойчивых микроорганизмов. Исследования микроорганизмов из клинического материала на устойчивость проведены к 48 дезинфицирующим средствам 15 групп с различными действующими веществами. В работе использованы описательно-оценочные эпидемиологические методы исследований.

\section{РЕЗУЛЬТАТЫ И ИХ ОБСУЖДЕНИЕ}

Проведенное изучение динамики заболеваемости ИСМП в многопрофильной больнице свидетельствовало о стабильности показателей, которые составляют от 0,13 до 0,14 на 1000 пациентов. Для оптимизации эпидемиологического надзора за ИСМП и повышения әффективности противоэпидемических мероприятий разработан алгоритм дезинфектантоустойчивости микроорганизмов, выделенных из клинического материала пациентов, как часть микробиологического мониторинга многопрофильной больницы (рис. 1).

Общее руководство микробиологического мониторинга обеспечивает комиссия по ИСМП, в состав которой, наряду с ведущими специалистами, входят главный госпитальный эпидемиолог и заведующий микробиологической лабораторией. Госпитальный эпидемиолог 


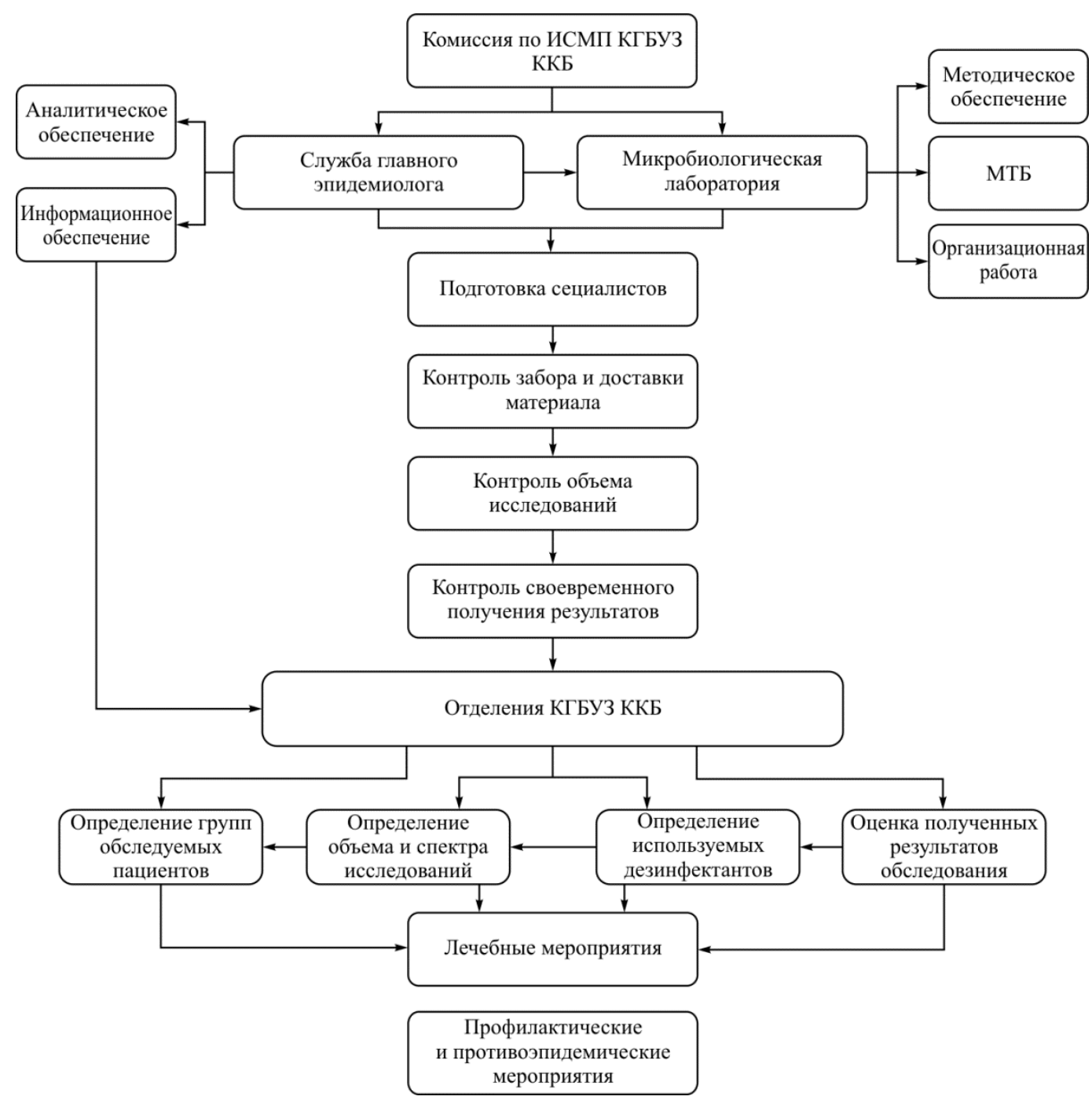

Рис. 1. Алгоритм мониторинга дезинфектантоустойчивости микроорганизмов, выделенных из клинического материала в многопрофильной медицинской организации

определяет информационное обеспечение, а именно: планируемый объем и перечень исследований согласно патологии пациентов и эпидемиологической ситуации в отделениях. Специалисты отдела проводят оперативный и ретроспективный анализ информации, полученной из отделений и лабораторий, корректировку исследований и противоэпидемических мероприятий. Микробиологическая лаборатория обеспечивает организа- цию микробиологических исследований согласно планируемым объемам и современным методикам. Совместно осуществляется подготовка специалистов отделений по микробиологическому мониторингу, контроль за объемом, забором, доставкой и получением результатов исследований. Между отделениями и эпидемиологической службой осуществляется информационное обеспечение. 
При введении мониторинга дезинфектантоустойчивости микроорганизмов, выделенных из клинического материала пациентов, отмечен рост количества исследований с 2013 по 2016 г. в 2,6 раза (рис. 2). За изучаемый период увеличилось количество положительных результатов исследований в 5,9 раза. При этом в динамике дезинфектантоустойчивости культур, выделенных из клинического материала, отмечается рост с 2013 по 2015 г. в 3,7 раза, со снижением в 2016 г. на $62,0 \%$.

Анализ мониторинга дезинфектантоустойчивости микроорганизмов, выделенных из клинического материала пациентов в 2013-2016 гг., свидетельствует о значительном росте Kl. pneumoniae (в 5,5 раза), $P$. aeruginosa (в 3,75 paza), Acinetobacter spp. (в 2,3 раза), E. coli (в 29,7 раза) (таблица).



Рис. 2. Динамика клинических микробиологических исследований в многопрофильной медщинской организащии в 2014-2016 г2.

\section{Результаты микробиологического мониторинга дезинфектантоустойчивости микроорганизмов, выделенных из клинического материала в многопрофильной медицинской организации в 2013-2016 гт.}

\begin{tabular}{|c|c|c|c|c|c|c|c|c|c|c|c|c|}
\hline \multirow{3}{*}{ Микроорганизм } & \multicolumn{3}{|c|}{2013} & \multicolumn{3}{|c|}{2014} & \multicolumn{3}{|c|}{2015} & \multicolumn{3}{|c|}{2016} \\
\hline & \multirow{2}{*}{ абс. } & \multicolumn{2}{|c|}{ в том числе } & \multirow{2}{*}{ абс. } & \multicolumn{2}{|c|}{ в том числе } & \multirow{2}{*}{ абс. } & \multicolumn{2}{|c|}{ в том числе } & \multirow{2}{*}{ абс. } & \multicolumn{2}{|c|}{ в том числе } \\
\hline & & ДУ & $\%$ & & ДУ & $\%$ & & ДУ & $\%$ & & ДУ & $\%$ \\
\hline Acinetobacter spp. & 26 & 6 & 23,1 & 114 & 33 & 28,9 & 125 & 34 & 27,2 & 60 & 13 & 21,7 \\
\hline Kl. pneumoniae & 34 & 11 & 32,4 & 146 & 53 & 36,3 & 133 & 38 & 28,6 & 187 & 21 & 11,2 \\
\hline P. aeruginosa & 40 & 15 & 37,5 & 61 & 9 & 14,8 & 44 & 7 & 9,4 & 150 & 16 & 10,7 \\
\hline E. coli & 3 & 1 & 33,3 & 41 & 4 & 10,3 & 51 & 8 & 9,8 & 98 & 3 & 3 \\
\hline St. aureus & 3 & - & 2,7 & 0 & - & 0 & 33 & 2 & 6 & 57 & 4 & 7 \\
\hline St. epidermidis & 0 & - & 0 & 0 & - & 0 & 9 & 2 & 22,2 & 5 & 1 & 20 \\
\hline Enterobacter spp. & 2 & 2 & 100 & 9 & 2 & 22,2 & 9 & 2 & 22,2 & 12 & 4 & 30 \\
\hline Enterococcus spp. & 0 & 0 & - & 0 & 0 & 0 & 0 & 29 & 6,2 & 33 & 3 & 9,1 \\
\hline Прочие & 3 & - & 2,7 & 28 & 3 & 10,7 & 32 & 12 & 37,5 & 15 & 8 & 53,3 \\
\hline Всего & 105 & 35 & 33,3 & 399 & 101 & 25,3 & 436 & 128 & 29,4 & 617 & 73 & 11,9 \\
\hline
\end{tabular}

П р и м е ч а н и е : ДУ - дезинфектантоустойчивые. 
При этом общая дезинфектантоустойчивость в 2016 г. сократилась в 2,8 раза, что свидетельствовало о повышении эффективности эпидемиологического надзора за формируемыми в стационаре госпитальными штаммами и мероприятий по смене используемых дезинфицирующих средств.

В 2016 г. количество культур, выделенных из клинического материала отделений многопрофильной больницы, составило 617 (1,57 на 1000 пациентов). Наибольший удельный вес в общей структуре выделенных культур был в отделениях хирургического профиля - 48,8 \%, в отделениях реанимации - 30,0\%, в терапевтических отделениях - 21,2 \%. В 5 отделениях терапевтического профиля выделена 131 культура. Наибольший удельный вес был в гематологическом отделении - 61,8 \% и токсикологическом - 29,0 \%. Показатели на тысячу пациентов составили 3,1 и 1,2 соответственно. Наибольшее количество положительных результатов было получено из промывных вод 74,8 \% (98), из мокроты - 9,2 \%, крови на стерильность - 12,9 \%, мочи на стерильность 2,7 \%, плевральной жидкости - 1,0 \%.

Наиболее высок удельный вес Kl. pneumoniae - 32,1 \%, P. Aeruginosa - 24,4\% и E. coli - 22, $1 \%$.

В 10 отделениях хирургического профиля выделена 301 культура, в том числе наибольшее количество в операционных блоках - 24,9 \% (75), гинекологическом отделении - 14,0 \%, ортопедическом - 12,9\%, ЛОР-отделении - 10 \%. Наибольшее количество культур в представленных отделениях было выделено из промывных вод 131 (25,3\%), мочи на стерильность - 3,3\%.

Как и в отделениях терапевтического профиля, в хирургических преобладали Kl. pneumoniae - 30,0 \%, P. aeruginosa 24,6\%, Acinetobacter spp. - 10,3\%.
В шести отделениях реанимационного профиля из клинического материала выделено 185 культур, наибольшее количество в отделениях нейрореанимации - 57 (30,8 \%), кардиореанимации - 43 (23,2 \%), отделениях реанимации, пересадки почки - 40 (21,6 \%). Клинический материал представлен промывными выводами - 108, кровью на стерильность - 58, мочой на стерильность - 11 , мокротой - 4,3. Как и в других отделениях, из клинического материала преимущественно были выделены $P$. aeruginosa - 23,8 \%, Kl. pneumoniae - 29,7 \%, E. coli - 16,2 \%, Acinetobacter spp. - 11,4\%, St. aureus - 7,6\%.

С целью определения эпидемиологически значимой микрофлоры изучена ее дезинфектантоустойчивость. Удельный вес дезинфектантоустойчивой флоры в целом по больнице составил 11,9 \%, в том числе и в терапевтических отделениях - 5,3\%, хирургических $-4,7 \%$, реанимационных - 28,1\%. Структура возбудителей представлена на рис. 3.


Acinetobacter spp.
$\square$ Enterococcus spp.
- Kl. pneumoniae
$\square$ St. aureus
i $P$. aeruginosa
$\mathbb{\otimes}$ Прочие

- E. coli

Рис. 3. Структура дезинфектантоустойчивых микроорганизиов, выделенных из клинического материала в многопрофильной медицинской организащии 
Дезинфектантоустойчивая флора определялась тремя основными возбудителями: $P$. aeruginosa и Kl. pneumoniae - 21,9 \% соответственно, Acinetobacter spp. - 17,8\%. Наиболее часто дезинфектантоустойчивость определялась к группе четвертичных аммониевых соединений (ЧАС) - 41,1 \%, в Том числе ЧАС + амины - 24,7 \%, ЧАС + альдегид - 6,8 \%, только ЧАС - 9,6 \%. На втором месте были хлорсодержащие препараты - 21,9 \% (сульфохлорантин, «Дез-хлор»). Более низкие показатели получены в группах кислородосодержащих и комплекса кислот - по 9,6 \% соответственно. К ЧАС наиболее резистентными были $K l$. pneumoniae, $P$. aeruginosa, Acinetobacter $s p p$. У этих возбудителей отмечалась полирезистентность к ЧАС и к хлорсодержащим препаратам; к хлорсодержащим препаратам y Acinetobacter spp., Kl. pneumoniae, $P$. aeruginosa, E. coli. Полученные результаты мониторинга дезинфектантоустойчивости микроорганизмов, выделенных из клинического материала, использовались эпидемиологом для предупреждения формирования и распространения госпитальных штаммов.

\section{Выводы}

1. Разработанный алгоритм мониторинга дезинфектантоустойчивости, микроорганизмов, выделенных из клинического материала, на основе программного обеспечения позволил:

- увеличить количество микробиологических исследований из клинического материала с 2013 по 2016 г. в 2,6 раза;

- сократить общее количество дезинфектантоустойчивых микроорганизмов в 2016 г. по отношению к 2015 г. на 62,0\%.

2. Наибольший удельный вес выделенных культур микроорганизмов был в отделе- ниях хирургического профиля - 48,8%, в отделениях реанимационного профиля 30,0 \%, терапевтического профиля - 21,2\%. Клинический материал, из которого получено наибольшее количество положительных результатов бактериологических исследований: промывные воды (от 74,8 \% в терапевтических отделениях до 43,5 \% в отделениях хирургического профиля), кровь на стерильность (от 2,7 \% в терапевтических отделениях до 31,4 \% в реанимационных).

3. Микрофлора, выделенная из клинического материала, представлена преимущественно $P$. aeruginosa - 24,0 \%, Kl. pneumoniae $30,0 \%$, E. coli - от 12,9 до 22,1 \%, St. aureus - от 3,0 до 7,6\%.

4. Проведенные исследования на дезинфектантоустойчивость к 48 наименованиям 15 групп химических соединений свидетельствовали о нарастании резистентности к ЧАС - 41,1\%, в том числе ЧАС + амины 24,7 \%, хлорсодержащим - 21,9 \%. Наиболее высокой резистентность культур к используемым дезинфектантам была у Acinetobacter spp., Kl. pneumoniae, P. aeruginosa и E. coli.

\section{БИБЛИОГРАФИЧЕСКИЙ СПИСОК}

1. Благонравова А.С., Ковалишена О.В. Результаты мониторинга устойчивости к дезинфектантам микрофлоры лечебно-профилактических учреждений. Главная медицинская сестра 2009; 9: 79-82.

2. Брусина Е.Б. Теоретические, методологические и организационные основы эпидемиологического надзора за ГГСИ в хирургии (эпидемиологические, клинические и микробиологические исследования). ГОУ ВПО «Кемеровская государственная медицинская академия Росздрава». Омск 1996; 32. 
3. Руководство по инфекционному контролю в стационаре. Международное общество по инфекционным болезням (ISID) $2003 ; 13-15$.

4. СанПиН 2.1.3.2630-10. Санитарноэпидемиологические требования к организациям, осуществляющим медицинскую деятельность, available at: http://docs.cntd.ru/ document/902217205

5. Сергевнин В.И., Маркович Н.И., Авдеева Т.В., Волкова Э.О., Решетникова Н.И., Зуева Н.Н., Азанов П.Б., Ключарева Н.М. Чувствительность возбудителей гнойно-септических инфекций к дезинфектантам (предварительные итоги работы региональной референслаборатории). Дезинфекционное дело 2011; 4: 26-29.

6. Шестопалов Н.В., Пантелеева Л.Г., Абрамова И.М. Обоснования выбора химических дезинфицирующих и стерилизующих средств для применения в организациях, осуществляющих медицинскую деятельность: МР 3.5.1.-11. Федеральный центр гигиены и эпидемиологии Роспотребнадзоpa России, available at: http://1piar.ru/ folio/folio-61800.php
7. Шкарин В.В., Ковалишена О.В., Благонравова А.С., Башкатова Л.А., Княгина О.Н., Окунь И.Н., Широкова, И.Ю., Саперкин Н.В., Иванова Н.Ю., Чанышева Р.Ф. Мониторинг устойчивости бактерий к дезинфицирующим средствам в медицинских организациях: федеральные клинические рекомендации. M. 2014, available at: http://nasci.ru/_resources/ directory/199/common/Monitoring_ustoichivo sti.pdf

8. Шкарин В.В., Ковалишена О.В., Благонравова А.С., Воробъева О.Н., Разгулин С.А., Алексеева И.Г., Саперкин Н.В., Башкатова Л.А., Окунь И.Н., Иванова Н.Ю., Широкова И.Ю. Мониторинг устойчивости микроорганизмов к дезинфектантам в лечебно-профилактических учреждениях: метод. рекомендации. Н. Новгород 2009.

9. Шкарин В.В., Саперкин Н.В., Ковалишена О.В., Благонравова А.С., Широкова И.Ю., Кулюкина А.А. Мониторинг устойчивости микроорганизмов к дезинфектантам. Итоги и перспективы. Медицинский альманах 2012; 3: 122-125.

Материал поступил в редакцию 10.08.2018 